\title{
Serological Probes for Some Foot-and-Mouth Disease Virus Nonstructural Proteins
}

\author{
MICHAEL TESAR, HANS-GERHARD BERGER AND OTFRIED MARQUARDT \\ Federal Research Center for Virus Diseases of Animals, Tübingen, Federal Republic of Germany
}

Received February 8, 1989

Accepted March 29, 1989

Requests for reprints should be addressed to Otfried Marquardt, Federal Research Center for Virus Diseases of Animals, P.O. Box 1149. D-7400 Tübingen, Federal Republic of Germany.

Key words: expression cloning, foot-and-mouth disease virus, non-structural proteins

\begin{abstract}
Foot-and-mouth disease virus (FMDV) $\mathrm{O}_{1}$ Kaufbeuren-specific cDNA fragments were subcloned into the $E$. coli expression vector pRIT.2T. Fusion proteins thus produced in bacteria were purified by affinity chromatography and inoculated into rabbits. Three sera thus obtained were found to be monospecific for FMDV proteins $3 \mathrm{~A}, 3 \mathrm{C}$, and 3D, respectively. Two others were prevalently directed against protein $2 \mathrm{C}$, but in addition, either to protein $2 \mathrm{~B}$ or to protein $3 \mathrm{~A}$. Five out of six mature nonstructural virus proteins can therefore be separately investigated in FMDV-infected cells, either by indirect immunofluorescence or by radioimmunoprecipitation. Immunofluorescence shows all investigated proteins to be located exclusively in the cytoplasm. One of them, protein $2 \mathrm{C}$, transiently forms aggregates at the periphery of cells. Radioimmunoprecipitation confirmed current knowledge on maturation of FMDV proteins. It was further used to characterize postinfectional sera with regard to FMDV-specific antibodies. Cattle and guinea pig were found to have responded differently to FMDV nonstructural antigens. Furthermore, antigenicity of yet to be described FMDV polypeptides was observed in the guinea pig.
\end{abstract}

\section{Introduction}

Foot-and-mouth disease virus (FMDV) is a separate genus within the picornaviruses. The virions are composed of the four capsid proteins VP1 to VP4 and of one molecule of single-stranded RNA, which serves as the mRNA after infection. Translation utilizes a single open reading frame and results in a primary product of 


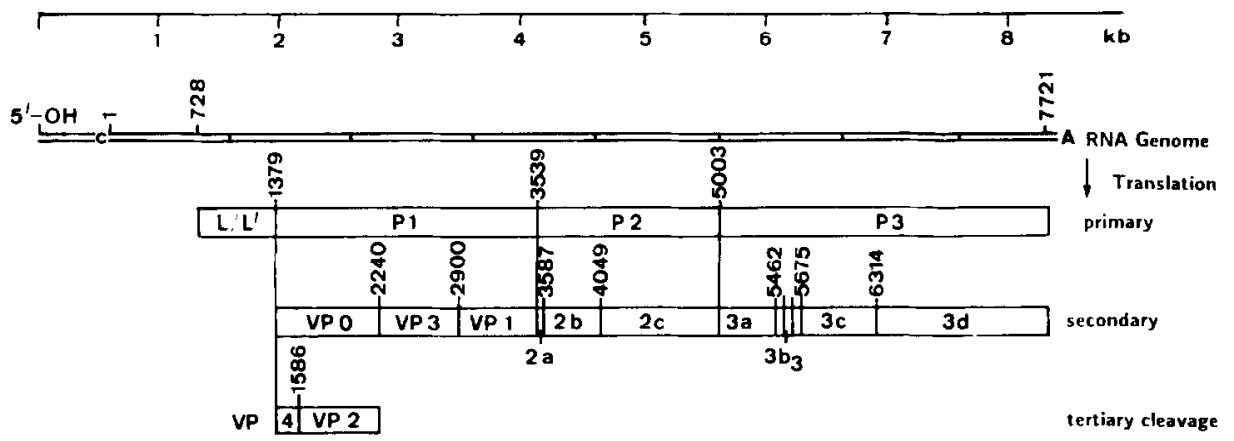

Fig. 1. Correlation of mature FMDV translation products to the viral genome. The FMDV genome is drawn in a kilobase (kb) scale. The homopolymeric tracts of cytidylic $(\mathrm{C})$ and adenylic $(\mathrm{A})$ acid are indicated. Sequence numbering begins with $1,3^{\prime}$-adjacent to the poly $(C)$ tract, in agreement with the UWGCG data base. The long open reading frame is marked by nucleotides 728 and 7721 . Products of primary, secondary, and tertiary cleavage of the translate are indicated by the first nucleotide of their amino-terminal codon. The designation of nonstructural proteins follows generally accepted suggestions, whereas structural proteins are traditionally designated.

about $250 \mathrm{kD}$. This is the precursor for both capsid and nonstructural proteins (1). The biochemical pathway of FMDV protein maturation has been elucidated $(2,3)$. Apart from the structural proteins, six to seven mature nonstructural proteins and four such peptides $(4,5)$ are distinguished. A correlation of mature FMDV translation products to the viral genome, as well as the sequence of proteolytic events in protein maturation, is illustrated for FMDV strain $\mathrm{O}_{1}$ Kaufbeuren $\left(\mathrm{O}_{1} \mathrm{~K}\right)$ in Fig. 1 .

As a consequence of the FMDV translation strategy, all proteins are produced simultaneously in equimolar amounts. Consequently, sera of guinea pigs recovered from FMD have been found to contain antibodies directed against a variety of virus proteins $(3,6,7)$ and do not enable separate evidence of the different FMDV proteins in infected cells. Successful efforts have been made to raise monospecific antisera for each of the known FMDV nonstructural proteins by inoculating either FMDV proteins purified from infected cells (3) or bacterially synthesized and purified fusion proteins (8). Production of FMDV antigens by recombinant DNA expression principally avoids cross-contamination. This approach has also been followed by us, but by use of a different bacterial expression system and of cDNA restriction fragments that encode only parts of FMDV proteins. The expression vector used, pRIT-2T (9), encodes the immunoglobulinbinding domain of Staphylococcus aureus protein A. FMDV-specific fusion proteins produced can thus he detected and purified by immunoglobulin. Proteins are purified nondenatured and may therefore be antigenically related to authentic virus proteins, although only consisting of parts of these. The anti-FMDV specificity of five sera thus obtained was demonstrated by indirect immunofluorescence and radioimmunoprecipitation with FMDV-infected cells. These 
antisera were used to identify FMDV-specific antibodies within postinfection guinea pig and cattle sera.

\section{Materials and methods}

Expression cloning of FMDV cDNA fragments

FMDV $\mathrm{O}_{1} \mathrm{~K}$-specific cDNA has been cloned in $E$. coli (10), sequenced (11), and recombined according to the authentic FMDV $\mathrm{O}_{1} \mathrm{~K}$ gene order in vitro in the plasmid pVP1-Po1 (12) (Fig. 2A). This plasmid was the source for five restriction fragments generated by the enzymes $X h o I$ and $S a l l$ (fragments A to F in Fig. 2A). The restriction fragments were separated by agarose gel electrophoresis and eluted electrophoretically from excised gel fragments in the Biotrap apparatus as recommended by the supplier (Schleicher \& Schuell, Dassel, FRG). The isolated fragments $A$ to $E$ were subcloned into the expression vector pRIT-2T (9), which had been linearized for that purpose by the enzyme $S$ all in its multiple cloning site (MCS in Fig. 2B). Subcloning occurred in E. coli C600 bacteria, which harbor lysogenic wild-type phage lambda and therefore prevent transcription from the right lambda promoter in pRIT·2T and derivatives. PT controls expression of recombinant DNA. The orientation of inserts was analyzed by restriction enzyme digestion of plasmids purified from subclones (data not shown). The enzymes are specified in the legend to Fig. 2. Plasmids were designated pRIT.A, pRIT·b, pRIT.C, pRIT.D, and pRIT $\cdot E$. Their relevant parts are drawn in Fig. $2 \mathrm{~B}$.

Fragments $\mathrm{A}, \mathrm{C}, \mathrm{D}$, and $\mathrm{E}$ thus elongate the open reading frame in front of MCS, which encodes the immunoglobulin-binding domain of Staphylococcus aureus protein A. Fragment B, however, is out of frame. Appropriate fusion of reading frames of fragment $B$ and protein $A$ in pRIT $b$ was achieved by opening the unique BamHI site within MCS, generating blunt ends by filling in with Klenow enzyme and ligating the blunt ends by T4 DNA ligase. The techniques used have previously been described (12). The plasmid obtained after subcloning was designated pRIT $B$ (Fig. 2B). Fragment $C$ is specific for FMDV proteins $2 \mathrm{C}$ and $3 \mathrm{~A}$ (Fig. 2A). Its $2 \mathrm{C}$-specific sequence was deleted from $\mathrm{pRIT} \cdot \mathrm{C}$ by digestion with the restriction enzyme EcoRI, which cuts in MCS and at the $5^{\prime}$ end of the $3 \mathrm{~A}$ specific sequence. The truncated vector was purified by electrophoresis and religated by insertion of the SmaI-EcoRI decamer linker 5' AATTCCCGGG (purchased from Biolabs, Schwalbach, FRG). Plasmids obtained after subcloning were found to contain the linker because linearization with the restriction enzyme SmaI was achieved (results not shown). Plasmids were designated pRIT ${ }^{\delta} \mathrm{C}$. Fragment D is specific for FMDV proteins 3B, 3C, and 3D (Fig. 2A). The 3D-specific sequence was deleted by cleavage of pRIT'D with the enzyme PstI, which cuts within the 3C-encoding sequence and MCS. The truncated vector was religated and subcloned. The resulting plasmid was designated pRIT· $\mathrm{D}^{\delta}$ (Fig. 2B). 
A

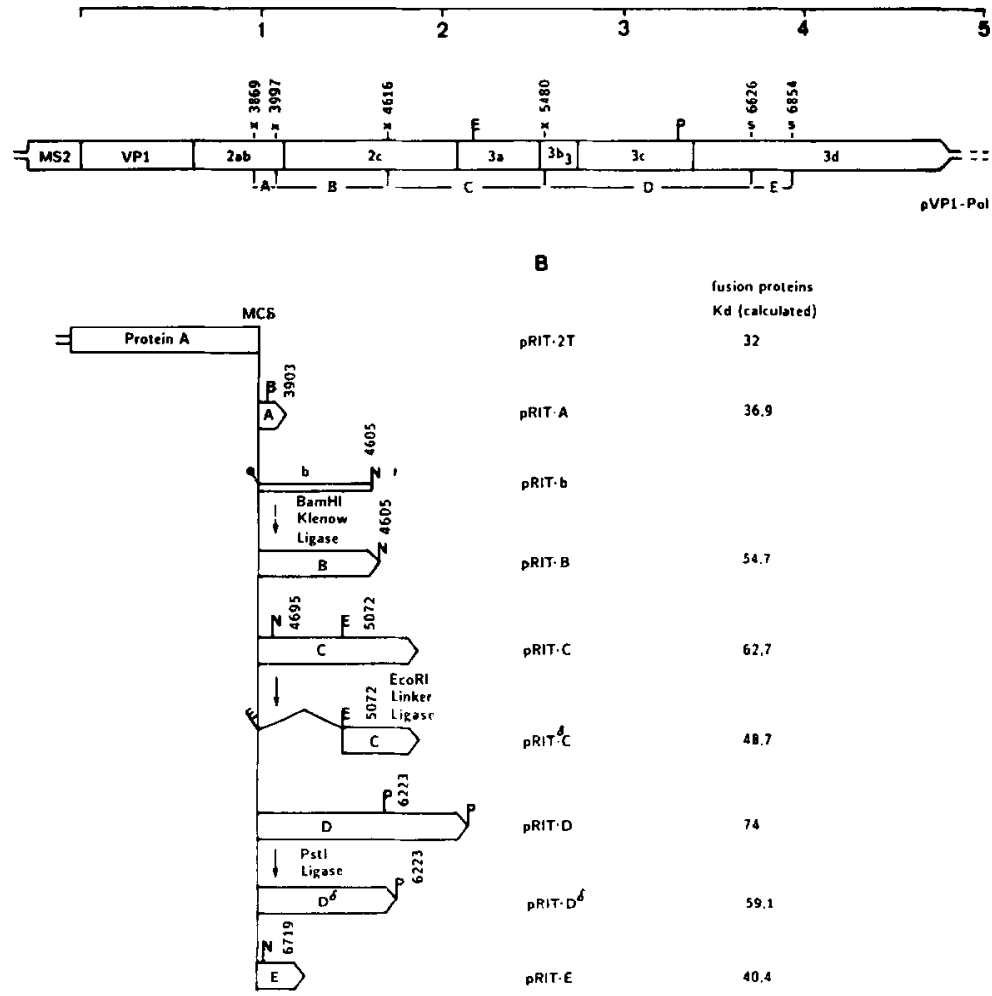

Fig. 2. Expression-cloning of FMDV cDNA restriction fragments. The FMDV-specific open reading frame of the plasmid pVP1-Pol (12) is shown in Panel A in a kilobase scale. The sites for restriction enzymes $\mathrm{Xhol}(\mathrm{x})$ and Sall (s) used to generate restriction fragments $\mathrm{A}$ to $\mathrm{E}$ are numbered. Sites for EcoRI (E) and PstI (P) are also indicated. Panel B shows the relevant open reading frame of the expression-cloning vector pRIT $2 T^{\prime}$ (9) and the multiple cloning site (MCS) at its $3^{\prime}$ end in the top row. The Sall site used here for subcloning is indicated by the vertical line. Insertion of fragments $A$ to $E$ is drawn in the following rows. Restriction enzymes BglII (B), NcoI $(\mathrm{N})$, and Pstl $(\mathrm{P})$ allowed the determination of the orientation. Nucleotides that specify the cleavage sites are indicated. DNA

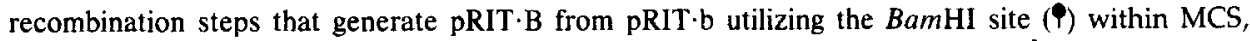
$\mathrm{pRIT} \cdot{ }^{\delta} \mathrm{C}$ from $\mathrm{pRIT} \cdot \mathrm{C}$ by deleting the $E c o \mathrm{RI}(\mathrm{E})$ restriction fragment, and $\mathrm{pRIT} \cdot \mathrm{D}^{\delta}$ from $\mathrm{pRIT} \cdot \mathrm{D}$ by deleting the PstI (P) restriction fragment are indicated. The molecular weights calculated for individual fusion proteins are listed on the right.

Analysis of FMDV-specific gene expression in E. coli

Expression of recombinant plasmids was achieved by their transfer into $E$. coli HB101 already harboring pCI857. The latter plasmid encodes the thermolabile mutant CI857 (13) of lambda phage repressor CI. Transcription, and therefore gene expression, is inhibited in cultures grown at $28^{\circ} \mathrm{C}$ and is induced by a shift of 
the growth temperature to $42^{\circ} \mathrm{C}$. Selection for the presence of pCI857 and pRIT derivatives was achieved by addition of kanamycin and ampicillin to Luria broth medium.

Cultures containing either $\mathrm{pRIT} \cdot 2 \mathrm{~T}$ or its recombinant derivatives $\mathrm{A}$ to $\mathrm{E}$ were analyzed for the presence of protein-A-specific protein before and after induction of expression. This was done with culture aliquots from logarithmic growth phase corresponding to 0.3 optical density ${ }_{620}$ units. Samples were precipitated by trichloroacetic acid and resuspended in alkaline Laemmli buffer (unbuffered instead of HCl-buffered Tris) prior to sodium dodecylsulfate polyacrylamide gel (either $15 \%$ homogeneously or gradients between $8 \%$ and $15 \%$ in acrylamide) electrophoresis $\left(\mathrm{NaDodSO}_{4}-\mathrm{PAGE}\right)$ as described earlier (12). Proteins were electroblotted onto nitrocellulose sheets following a standard protocol (14). Detection of protein A-specific proteins required preincubation ( $2 \mathrm{hr}$ R.T.) of nitrocellulose with phosphate-buffered saline (PBS) containing $1 \%$ bovine serum albumin (BSA), washing with PBS, and incubation overnight at room temperature (R.T.) with $20 \mu \mathrm{l}$ peroxidase-conjugated antibodies (Nordic Immunological Reagents, Tilburg, The Netherlands) in PBS with $0.1 \%$ BSA. After extensive washing with PBS adjusted to $0.1 \%$ Triton- $\mathrm{X} 100,25 \mu \mathrm{H}_{2} \mathrm{O}_{2}$, and $15 \mathrm{mg}$ chloronaphtol were added to the nitrocellulose and incubated in $100 \mathrm{ml} 0.5 \times \mathrm{PBS} / 2.5 \mathrm{mM}$ Tris- $\mathrm{HCl}$, $\mathrm{pH}$ 7.5. This started the enzymatic reaction, which resulted in protein staining. This technique takes advantage of the strong binding of immunoglobulin to protein A.

\section{Purification of fusion proteins}

E. coli clones were grown in $400 \mathrm{ml}$ to $0.3 \mathrm{OD}_{620}$ at $28^{\circ} \mathrm{C}$. The temperature was shifted to $42^{\circ} \mathrm{C}$ and growth was continued to $1.4 \mathrm{OD}_{620}$. Bacteria were collected by centrifugation at $6000 \mathrm{~g}$ for $5 \mathrm{~min}$ and resuspended in $6 \mathrm{ml}$ of binding buffer (150 $\mathrm{mM} \mathrm{NaCl} ; 50 \mathrm{mM}$ Tris- $\mathrm{HCl}, \mathrm{pH} \mathrm{8,6;0.2 \%} \mathrm{Nonidet} \mathrm{P} 40 ; 0.05 \% \mathrm{NaDodSO}_{4}$ ). The suspension was subjected to two cycles of shock-freezing and to twofold sonication for $15 \mathrm{sec}$ at $150 \mathrm{~W}$. Insoluble material was pelleted by centrifugation at $20,000 \mathrm{~g}$ for $30 \mathrm{~min}$, resuspended in $6 \mathrm{ml}$ of binding buffer, and sonicated once more. The supernatant after subsequent centrifugation was combined with the supernatant from the previous centrifugation and immediately used for affinity chromatography against immobilized immunoglobulin at $4^{\circ} \mathrm{C}$.

Immunoglobulin was precipitated overnight at $4^{\circ} \mathrm{C}$ from rabbit serum with ammonium sulphate ( $37 \%$ final concentration). The precipitate was collected by centrifugation at $20,000 \mathrm{~g}$ for $30 \mathrm{~min}$ and resuspended in $5 \mathrm{ml}$ PBS. Immunoglobulin was extracted by affinity chromatography to immobilized Staphylococcus aureus protein A, dialyzed extensively against PBS, and dried by lyophilization. Lyophilisate containing $17 \mathrm{mg}$ protein was resuspended in $25 \mathrm{ml}$ buffer containing 500 $\mathrm{mM} \mathrm{NaCl}, 100 \mathrm{mM} \mathrm{NaHCO} 3, \mathrm{pH} 8.3$ and coupled to $2.5 \mathrm{~g} \mathrm{CNBr}$-activated sepharose 4B (Pharmacia, Freiburg, FRG), as recommended by the supplier. Sepharose- 
coupled immunoglobulin was put into a column $(15 \times 0.9 \mathrm{~cm})$ connected to a pump and to a spectral photometer, and equilibrated with binding buffer.

Adsorption of protein-A-specific protein to immobilized immunoglobulin was allowed with a flow rate of $1 \mathrm{ml} / \mathrm{min}$ during repeated loading cycles. Unbound protein was then washed off the column with binding buffer until the baseline of absorption at $280 \mathrm{~nm}$ was reached. Detergents were removed by washing the column with $50 \mathrm{ml}$ containing $150 \mathrm{mM} \mathrm{NaCl}$ and $50 \mathrm{mM}$ Tris- $\mathrm{HCl}, \mathrm{pH}$ 8.6. Proteins retained in the column were eluted by elution buffer $(50 \mathrm{mM}$ diethylamine, $500 \mathrm{mM} \mathrm{NaCl}, 0.05 \% \mathrm{NaN}_{3}, \mathrm{pH} 11.8$ ). Elution of proteins was detected by an increase of absorption at $280 \mathrm{~nm}$ and continued until the baseline was reached. The eluted material was analyzed by $\mathrm{NaDodSO}_{4}-\mathrm{PAGE}$ and used for immunization. Eluted proteins were as heterogeneous in size (not shown) as intracellular fusion proteins.

\section{Immunization}

Rabbits of about $3 \mathrm{~kg}$ weight were inoculated intracutaneously with $20 \mu \mathrm{g}$ of purified fusion protein mixed with complete Freund's adjuvant. Protein concentrations were determined by the Biorad (Munich, FRG) method as recommended. BSA was used as a standard. Rabbits were boosted 4-7 times in intervals of 3 weeks with $50 \mu \mathrm{g}$ fusion protein and incomplete Freund's adjuvant according to a standard protocol (15). Samples of serum were taken before and after each inoculation.

Sera from a goat immunized with highly purified inactivated FMDV $\mathrm{O}_{1} \mathrm{~K}$, from a rabbit immunized with tissue culture supernatant of FMDV-infected BHK cells, and from animals (guinea pig and cattle) that had recovered from FMDV infection were kindly provided by B. Haas, O.C. Straub, and K. Strohmaier, Tübingen.

\section{Radiolabeling of virus proteins in infected cells}

Baby hamster kidney (BHK) 21 cells were grown as monolayers in $10-\mathrm{cm}^{2}$ dishes as described previously (16). Freshly grown $\mathrm{FMDV} \mathrm{O}_{1} \mathrm{~K}$ was added at a multiplicity of infection greater than 20 and removed 30 min later by washing. Early after observation of cytopathic effects (about $2 \mathrm{hr}$ postinfection), the cells were washed in methionine-free modified Eagle's medium (MEM, Sigma, Deisenhofen, FRG) and incubated therein together with $500 \mu \mathrm{Ci}\left[{ }^{35} \mathrm{~S}\right]$ methionine (Amersham Buchler, Braunschweig, FRG) for $30 \mathrm{~min}$. The medium was then exchanged with nonradioactive methionine-containing MEM and incubation was continued for an additional $90 \mathrm{~min}$. The cells were then washed and lysed using $1 \mathrm{ml}$ per dish of RITA buffer (10 mM Tris- $\mathrm{HCl}, \mathrm{pH} 7.5 ; 150 \mathrm{mM} \mathrm{NaCl} ; 1 \% \mathrm{Na}$ deoxycholate; $1 \%$ $\mathrm{NP40} ; 0.1 \% \mathrm{NaDodSO}_{4} ; 2 \mathrm{mM}$ L-methionine; $0.1 \%$ ovalbumin; $0.02 \% \mathrm{NaN}_{3} ; 1$ $\mathrm{mM}$ phenylmethylsulfonylfluoride). The cell lysate was sonicated 3 times for 10 
sec and centrifuged for $1 \mathrm{hr}$ at $160,000 \mathrm{~g}$. The supernatant was harvested, an aliquot assayed for trichloroacetic-acid-insoluble radioactivity, and stored at $-70^{\circ} \mathrm{C}$ until use. As a control, mock-infected BHK cell cultures were radiolabeled and harvested according to the protocol outlined above.

\section{Immunoprecipitation}

Radiolabeled lysate corresponding to $10^{6} \mathrm{counts} / \mathrm{min}$ were made up to $30 \mu \mathrm{l}$ with RITA buffer, mixed with $10 \mu \mathrm{l}$ of antiserum and incubated for $1 \mathrm{hr}$ at room temperature and $1 \mathrm{hr}$ at $4^{\circ} \mathrm{C}$. Fifty microliters of a suspension of highly concentrated formalin-inactivated Staphylococcus aureus cells in RITA buffer were added, and incubation at room temperature was continued for $30 \mathrm{~min}$. Cells and material complexed to it were concentrated by centrifugation at $6000 \mathrm{~g}$ for $1 \mathrm{~min}$ and supernatants were discarded. Cells were resuspended in $500 \mu$ of fresh RITA buffer and washing was repeated 4 times. Final washing consisted of centrifugation through $500 \mu \mathrm{l} 30 \%$ sucrose in RITA buffer. The pellet was resuspended in $\mathbf{5 0}$ $\mu l$ Laemmli sample buffer, incubated at $56^{\circ} \mathrm{C}$ for $5 \mathrm{~min}$, and centrifuged $2 \mathrm{~min}$ at $13,000 \mathrm{~g}$. Supernatants thus depleted from cells were transferred to fresh reaction cups and subjected to $\mathrm{NaDodSO}_{4}$-PAGE. Following electrophoresis, gels were fluorographed (17), dried, and exposed for autoradiography with X-ray films (Kodak, XAR 5) at $-70^{\circ} \mathrm{C}$. These were automatically developed by a Sakura QX60 unit.

\section{Indirect immunofluorescence}

BHK cells were grown on sterile microscopic slides (Flow, Meckenheim, FRG) in $10-\mathrm{cm}^{2}$ dishes and infected with FMDV $\mathrm{O}_{1} \mathrm{~K}$ as described. After 110 to $130 \mathrm{~min}$ incubation, when cytopathic effects became visible, the slides were removed and incubated for $20 \mathrm{~min}$ in $3 \%$ paraformaldehyde, for $10 \mathrm{~min}$ in $3 \%$ paraformaldehyde with $0.2 \%$ Triton-X100, and 3 times for $5 \mathrm{~min}$ in PBS. One to $5 \mu$ lof antisera were made up to $100 \mu \mathrm{l}$ with PBS, dropped on individual fields on the slide, and incubated for $30 \mathrm{~min}$ at room temperature. Slides were then washed 3 times for $5 \mathrm{~min}$ in PBS. Goat anti-rabbit $\operatorname{IgG}, \mathrm{F}\left(\mathrm{ab}^{\prime}\right)_{2}$ conjugated with fluoresceinisothiocyanate (Dianova, Hamburg, FRG) was diluted in PBS 100-fold and incubated with the slides for $30 \mathrm{~min}$ at room temperature. After washing 3 times in PBS, the slides were covered with glycerol or with $12 \%$ mowiol 488 (Hoechst); $200 \mathrm{mM}$ Tris, $\mathrm{pH} 8.5 ; 30 \%$ glycerol; and $0.1 \%$ paraphenylendiamin (Sigma) and kept in the dark for fluorescence microscopy. A Leitz Dialux 20 (Leitz, Wetzlar, FRG) equipped with a camera was used for microscopy using $495 \mathrm{~nm}$ light. Photographical documentation utilized Kodak ektachrome 400 films (about 1 min exposure). 


\section{Results}

Proteins expressed from FMDV-specific recombinant plasmids in $\mathrm{E}$. coli

Appropriate insertion of different $\mathrm{FMDV} \mathrm{O}_{1} \mathrm{~K}$-specific cDNA restriction fragments into $E$. coli expression vector pRIT-2T (9) (Fig. 2) should cause the production of fusion proteins after induction of gene expression. Their amino-terminal parts are identically formed by the immunoglobulin-binding domain of Staphylococcus aureus protein A, while the carboxy-termini should specify individual FMDV proteins. Due to the availability of the FMDV $\mathrm{O}_{1} \mathrm{~K}$ nucleotide sequence (11), the molecular weight of each fusion protein can be calculated. Calculations are provided in Fig. 2B. Fusion proteins of such molecular weights are produced as shown with culture aliquots after induction of gene expression subjected to $\mathrm{NaDodSO}_{4}$-PAGE and subsequently to Western blotting (Fig. 3). Goat immunoglobulin $\mathrm{G}$ conjugated with peroxidase was used as a probe for the constant protein-A-specific part of the fusion proteins $\mathrm{RIT} \cdot \mathrm{A}, \mathrm{RIT} \cdot \mathrm{B}, \mathrm{RIT} \cdot{ }^{\circ} \mathrm{C}$, RIT $\cdot \mathrm{C}$, $\mathrm{RIT} \cdot \mathrm{D}^{\delta}, \mathrm{RIT} \cdot \mathrm{D}$, and RIT $\cdot \mathrm{E}$. The slowest migrating proteins labeled in each slot

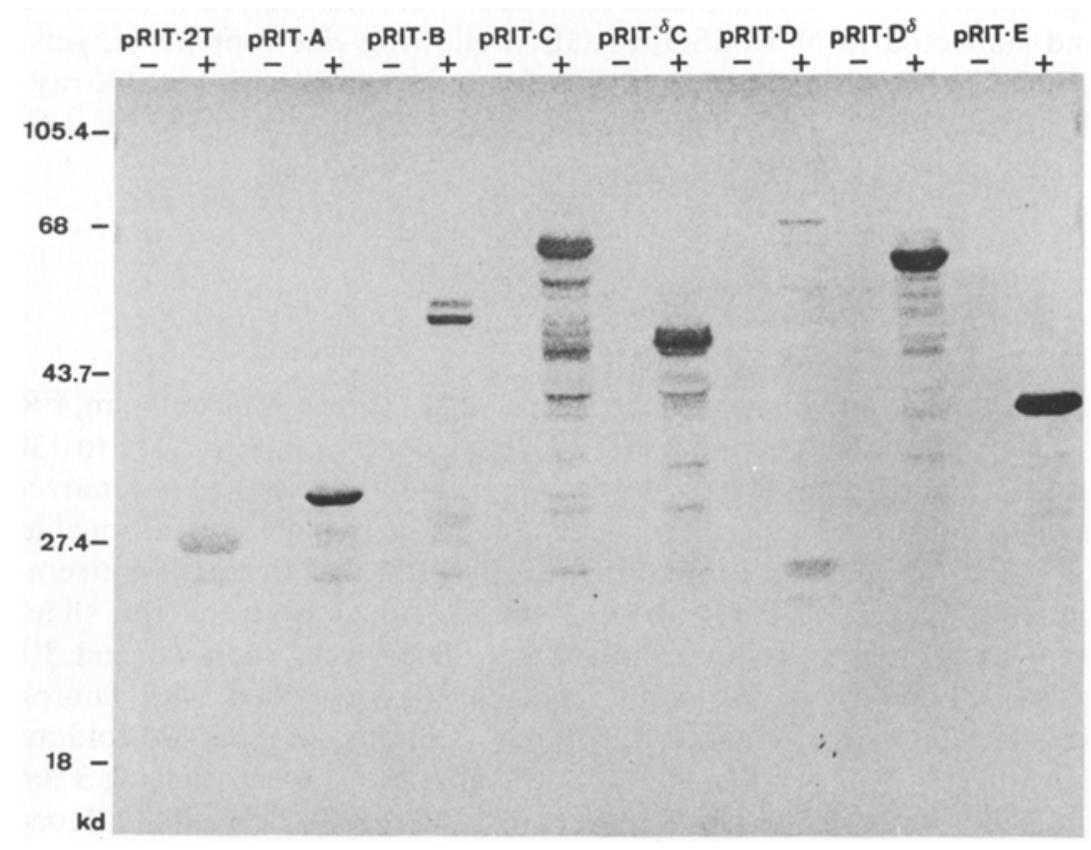

Fig. 3. Production of FMDV-specific fusion proteins by transformed bacteria. Plasmids used for transformation of bacteria are designated on top and are explained in Fig. 2. Culture aliquots removed without induction of gene expression are marked with $(-)$, and those removed after induction of gene expression are indicated by $(+)$. Protein molecular weight standards $(\mathrm{kD})$ are provided. The analysis used $\mathrm{NaDodSO}_{4} 8 \%$ to $15 \%$ polyacrylamide gradient gels and peroxidase-conjugated goat antibodies. 
are considered as the primary product of translation. The analysis indicates instability of FMDV-specific fusion proteins in $E$. coli, since protein-A-specific bands of different molecular weights are detectable. Production of fusion proteins without induction of expression is, as expected, not observable. FMDV specificity of these bacterially synthesized fusion proteins cannot be evidenced by serological methods because their protein A portion would interact with antibodies.

Fusion proteins expressed from pRIT $\cdot A, p R I T \cdot B, p R I T \cdot C, p^{2} I T \cdot{ }^{\circ} \mathrm{C}, \mathrm{pRIT} \cdot \mathrm{D}^{\delta}$, and pRIT $\mathrm{E}$ (Fig. 2B) were separately extracted from broken cells by affinity to immobilized immunoglobulin and inoculated in rabbits. Analysis of eluates by $\mathrm{NaDodSO}_{4}$-PAGE (data not shown) revealed virtually the same pattern of protein degradation as observed intracellularly (Fig. 3).

\section{Screening of rabbit immune sera for FMDV antibodies}

Aliquots of rabbit sera were removed before and after each inoculation and analyzed for FMDV $\mathrm{O}_{1} \mathrm{~K}$ specificity by indirect immunofluorescence with BHK cells $2 \mathrm{hr}$ postinfection. Specificity of immunofluorescence was controlled by rabbit preimmune sera (Fig. 4b) and mock-infected cells (not shown). One result obtained with anti-RIT $\cdot \mathrm{D}^{\delta}$ serum after six boosts is shown in Fig. 4a. It is representative of results also obtained with anti-RIT ${ }^{\circ} \mathrm{C}$ and anti-RIT:E (not shown). The cells show cytopathic effects (CPE) advanced to different stages, which are accounted for by replication of FMDV (1). In the late stage, the cytoplasm was shrunk and laterally attached to the nucleus, whereas earlier stages showed perinuclear concentration of viral antigen. Results obtained with anti-RIT·B and anti-RIT.C, which are both directed against FMDV protein $2 \mathrm{C}$ (Fig. 2), are shown in Figs. $4 \mathrm{c}$ and $4 \mathrm{~d}$. The antigens labeled here, most likely protein $2 \mathrm{C}$ and its precursors, aggregated frequently at the cell periphery during early stages of CPE and were not found later on (not shown). The pRIT $A$ fusion protein failed to raise anti-FMDV-specific rabbit sera.

\section{Characterization of FMDV antigens}

Sera were further analyzed for their capacity to precipitate radiolabeled FMDV $\mathrm{O}_{1} \mathrm{~K}$ proteins from lysates of infected cells. Radioimmunoprecipitation was controlled by the use of lysates of mock-infected radiolabeled cells and by preimmune sera. Cell lysates were prepared $90 \mathrm{~min}$ after radiolabeling of proteins was stopped in order to allow post-translational maturation of FMDV proteins. Thus a protein pattern of reduced complexity was achieved. The extent to which mature FMDV $\mathrm{O}_{1} \mathrm{~K}$ proteins are labeled by incorporation of $\left[{ }^{35} \mathrm{~S}\right]$ methionine was deduced from the nucleotide sequence (11). FMDV proteins 3D, 2C, and 3C should be labeled most efficiently.

Results of immunoprecipitation with sera raised against the different fusion 

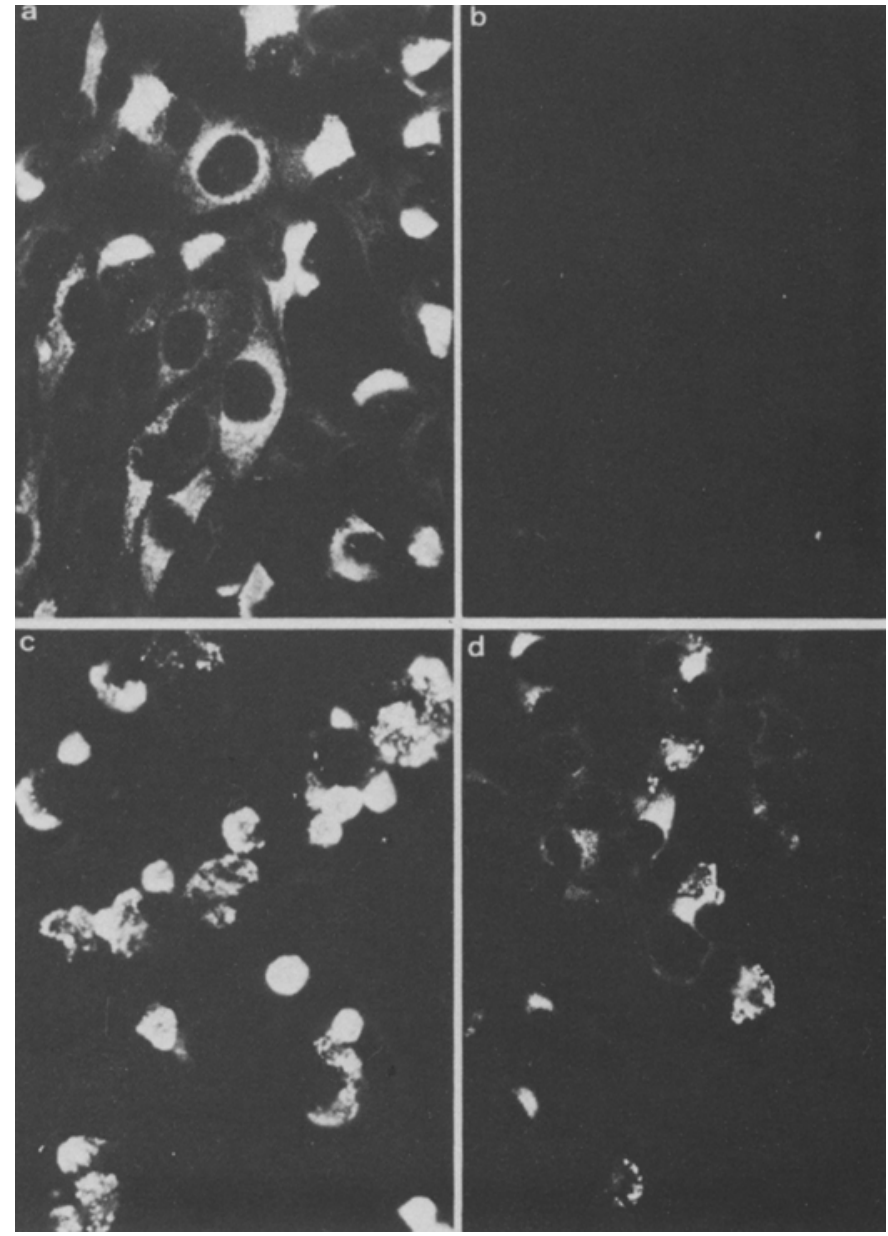

Fig. 4. Indirect immunofluorescence of FMDV-infected BHK cells. FMDV $\mathrm{O}_{1} \mathrm{~K}$-infected BHK cells were incubated with (a) rabbit anti-RIT $\cdot D^{\delta}$ serum, (b) rabbit pre-immune serum, (c) rabbit anti-RIT.C serum, and (d) rabbit anti-RIT.B serum in a 1:50 to $1: 100$ dilution. FITC-coupled goat-anti-rabbit fragment antibodies diluted 1:100 were used as second antibodies. Photographic documentation at 400-fold magnitude utilized Leitz microscope and Kodak ektachrome 400 film exposed for 60 seconds.

proteins are shown in Fig. 5. Anti-RIT.B, anti-RIT.C, anti-RIT $\cdot D^{\delta}$, and antiRIT $\cdot E$ were used in $A$, while anti-RIT ${ }^{\circ} \mathrm{C}$ compared to anti-RIT $\cdot B$ and anti-RIT.C was used in B. The patterns of labeled proteins in a lysate of mock-infected (A, lane 1) and infected (A, lane 2; B, lane 1) cells are also shown and are found to be clearly different. Anti-RIT $\cdot B$, anti-RIT $\cdot D^{\delta}$, and anti-RIT.E precipitated mainly one protein each ( $A$, lanes 7,13 , and 16$)$. These proteins comigrated with the most intensively labeled ones in extracts of infected cells and are thus identified as 
FMDV proteins $2 \mathrm{C}, 3 \mathrm{C}$, and $3 \mathrm{D}$ by a twofold line of evidence. Protein $3 \mathrm{C}$ was precipitated with low efficiency. The antiserum used was of apparently low respective titer despite a sixfold boost. Anti-RIT ${ }^{\delta} \mathrm{C}$ was expected to precipitate FMDV protein 3A and was found to precipitate two proteins (B, lane 9). Their difference in molecular weight of about $2.5 \mathrm{kD}$ is suggested to be due to one peptide $3 \mathrm{~B}$ being occasionally still fused to protein $\mathrm{A}$. These two 3A-specific proteins, together with protein $2 \mathrm{C}$, were also precipitated by anti-RIT $\cdot \mathrm{C}(\mathrm{A}$, lane 10; B, lane 6), however, additional protein coprecipitates. The FMDV specificity of all results was demonstrated by the failure of preimmune sera to precipitate FMDV proteins and of immune sera to precipitate cellular proteins (Fig. 5A, lanes $3,5,6,8,9,11,12,14,15 ; \mathrm{B}$, lanes $2,4,5,7,8,10$ ).

Since the fusion protein expressed from pRIT $\cdot A$ failed to elicit a FMDV protein

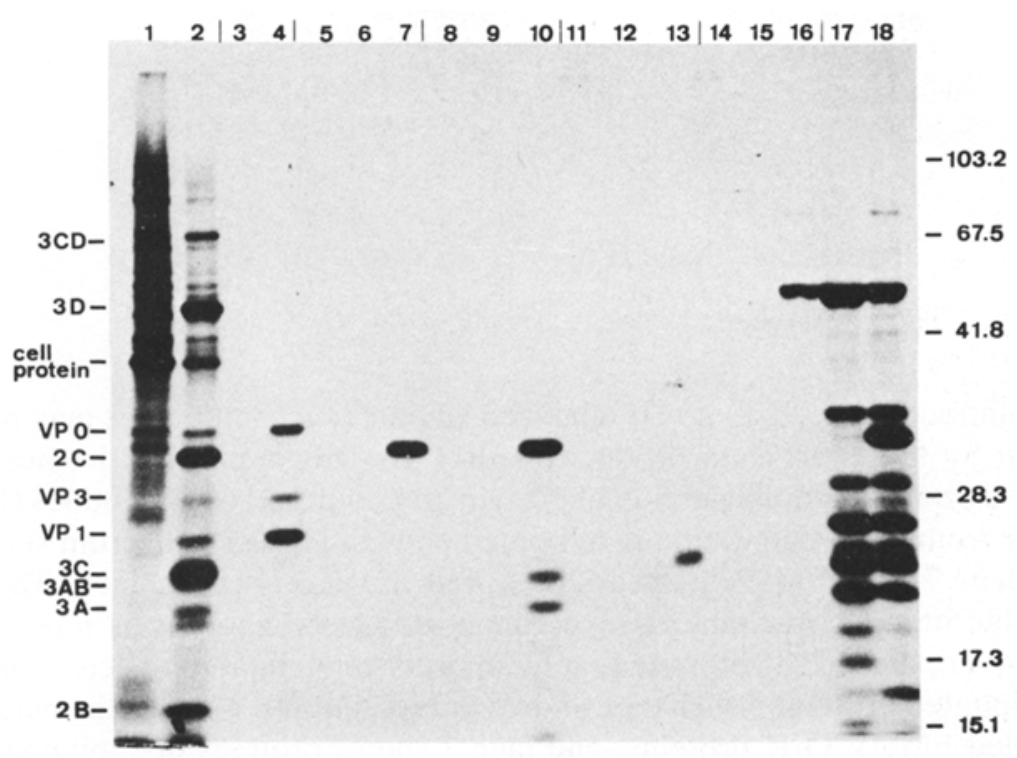

Fig. 5. Immunoprecipitation of radiolabeled $F M D V ~ O_{1} \mathrm{~K}$ proteins from cell extracts. Proteins were labeled with $\left[{ }^{35}\right.$ S $]$ methionine during synthesis and were separated by $\mathrm{NaDodSO}_{4}$-PAGE. The gel in $\mathrm{A}$ is $15 \%$ polyacrylamide, and that in $\mathrm{B}$ is $8 \%$ to $15 \%$ polyacrylamide. A shows proteins of FMDVinfected cells in lane 2 , those proteins precipitated by goat anti-inactivated capsid serum in lane 4 , by rabbit anti-RIT $B$ in lane 7 , by anti-RIT $\cdot C$ in lane 10 , by anti-RIT $\cdot D^{8}$ in lane 13 , by anti-RIT $\cdot E$ in lane 16 , by guinea-pig hyperimmune serum in lane 17 , and by bovine hyperimmune serum in lane 18 . In lanes $5,8,11$, and 14 respective rabbit pre-immune sera were used, and in lanes $3,6,9,12$, and 15 extracts of mock-infected (lane 1) and FMDV-specific antisera were used. (B) Lane 1 is identical to A, lane 2; lanes 2, 3, and 4 are identical to $A$, lanes 5, 7, 6; lanes 5, 6, 7 are identical to $A$, lanes, 8, 10, 9; lanes 11,12 are identical to $\mathrm{A}$, lanes 17,18 . Lane 8 is the mock lysate control for rabbit anti-RIT ${ }^{8} \mathrm{C}$ serum; for lanes 9 and 10 the lysate of infected cells and either anti-RIT ${ }^{.} \mathrm{C}$ or rabbit pre-immune serum was used. Gels were submitted to autoradiography for 3 (A) and 5 (B) days and autoradiograms are shown. 


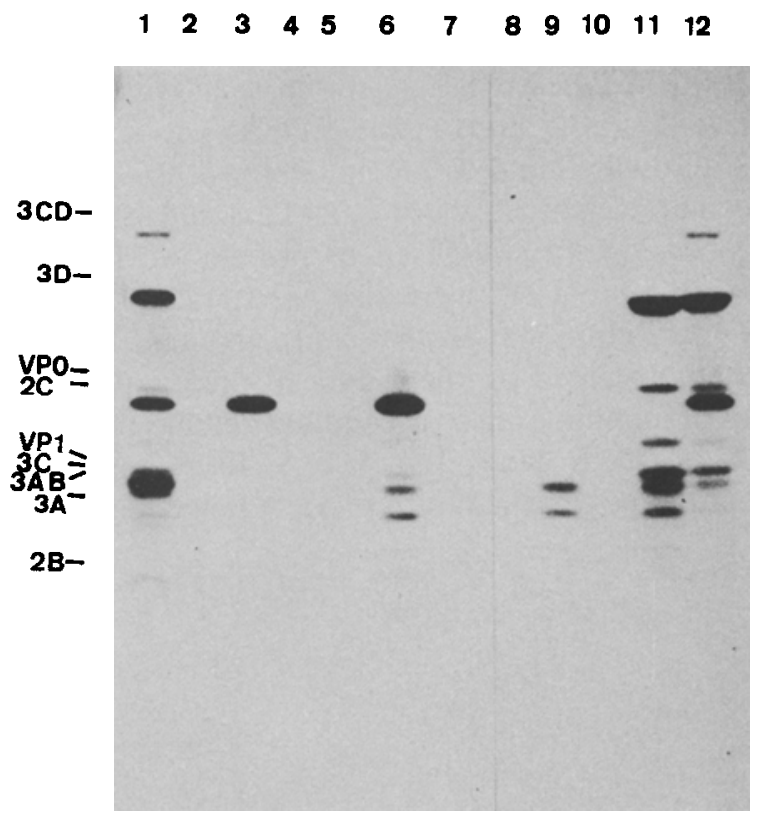

Fig. 5. (continued)

2B-specific antibody response, it was analyzed whether such antibodies may have been elicited by the expression product of pRIT $\cdot \mathrm{B}$. This is possible because it contains the carboxy-terminal peptide of protein $2 \mathrm{~B}$ composed of 17 residues (Fig. 2). It is clear from the precipitation result obtained with anti-RIT $B$ serum shown in Fig. 5A, lane 7, that FMDV protein $2 \mathrm{~B}$ is, if at all, poorly recognized. Therefore, when the immunoprecipitation experiment described above was repeated, the gel was overexposed to autoradiography in order to facilitate the detection of poorly precipitated protein. Results are shown in Fig. 6. Lane 1 shows the pattern of radiolabeled $\mathrm{FMDV} \mathrm{O}_{1} \mathrm{~K}$ proteins, and lane 3 shows proteins precipitated by rabbit anti-RIT'B serum. A protein of $16.5 \mathrm{kD}$ in molecular weight was observed here and was not observed elsewhere (lanes $2,4,5$ ). From this result one might conclude that anti-RIT $B$ serum is in fact directed against FMDV proteins $2 B$ and, prevalently, $2 \mathrm{C}$. There is a third protein precipitated by this serum, being slightly smaller than protein $2 \mathrm{C}(29.3 \mathrm{kD}$ instead of $32 \mathrm{kD})$. It must represent a truncated derivative of $2 \mathrm{C}$, since it is not precipitated by other sera.

Overexposure of precipitated viral capsid proteins (Fig. 6, lane 2) revealed differences from the comparable precipitation result shown before (Fig. 5A, lane 4). Coprecipitation of traces of the nonstructural proteins $3 \mathrm{D}, 2 \mathrm{C}$, and $3 \mathrm{C}$ here is explained by the use of the antiserum. It was raised against tissue-culture supernatant of FMDV-infected cells, which contains these proteins as well as virions released from lysed cells. The detection of capsid protein VP2 in Fig. 6 but not in Fig. 5A indicates the occasional intracellular presence of mature virions. Intensive VP1-specific signals, despite its low methionine content as compared to other 


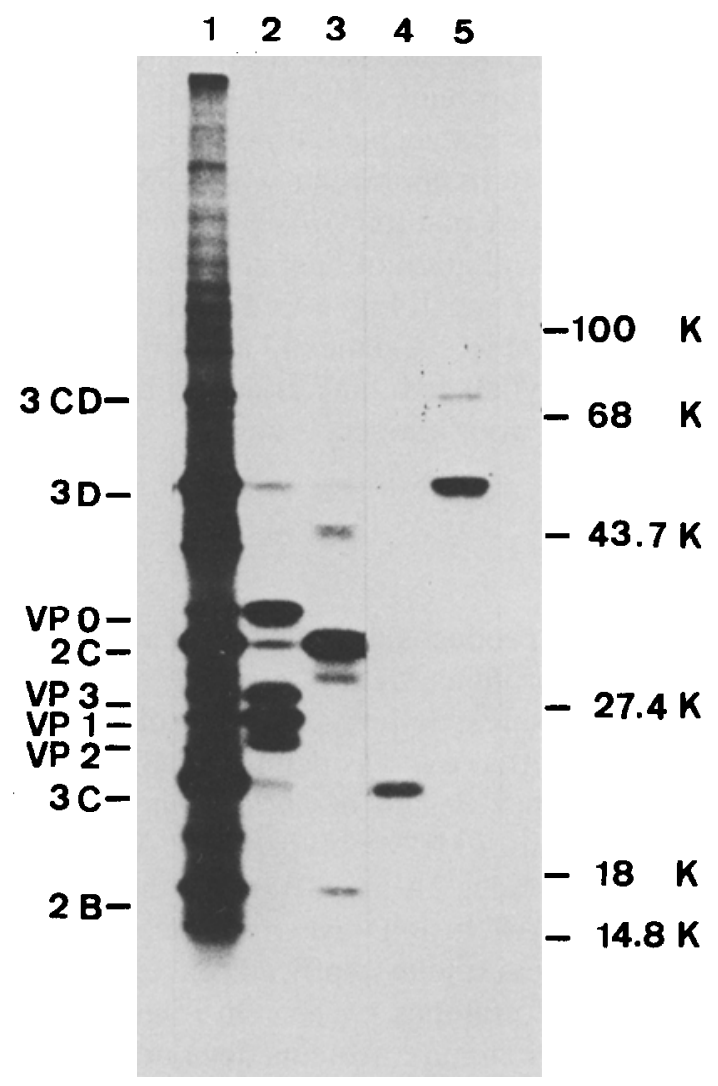

Fig. 6. Overexposure of radioimmunoprecipitation to autoradiography. The experimental setup is identical to that of Fig. 5B. An extract of FMDV-infected cells is shown in lane 1. Proteins precipitated from the extract by rabbit serum raised against the tissue culture supernatant of infected cells (lane 2),

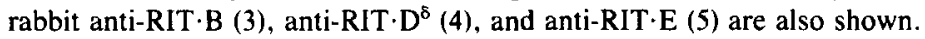

capsid proteins, reflects the generally accepted fact that VP1 is the major antigen in virions.

Differentiation, now being feasible between FMDV capsid proteins and five nonstructural proteins, was applied to analyze the infection-associated antigenicity of FMDV proteins. Postinfection sera obtained from a guinea pig that had recovered from infection with $\mathrm{FMDV} \mathrm{O}_{1} \mathrm{~K}$ (Fig. 5A, lane 17; Fig. 5B, lane 11) and a cow that had recovered from infection with FMDV $\mathrm{A}_{5}$ Bernbeuren (Fig. 5A, lane 18; Fig. 5B, lane 12) were available. Both sera precipitated capsid proteins VP0, VP3, and VP1 as well as noncapsid proteins $3 C D, 3 D, 3 C$, and two forms of $3 A$ (compare with lanes $4,16,13,10$ in $A$ ); however, some of these were precipitated with different efficiencies (Fig. 5B, lanes 11 and 12). The guinea pig exhibited a higher titer of antibodies for VP3 and both forms of protein 3A than the cow, while the converse was found with proteins $3 \mathrm{CD}$, and $2 \mathrm{C}$. Further differences concern- 
ing the smaller virus antigens were observed after a more sensitive analysis (Fig. $5 \mathrm{~A}$, lanes 17 and 18 ). Protein $2 \mathrm{~B}$ was efficiently precipitated by the cow, but not by the guinea pig serum, whereas proteins of about 19,18 , and $15 \mathrm{kD}$ in molecular weight were good antigens in the guinea pig but not in the cow. The $19 \mathrm{kD}$ protein could be protein $\mathrm{L}^{\prime}$ according to its molecular weight (8), while the smaller proteins can neither be explained as mature virus proteins according to molecular weight $(2,3,6,8)$ nor as a coprecipitation of host cell protein, since their synthesis was shut off (1) (compare lanes 1 and 2, Fig. 5A). Protein $3 \mathrm{C}$ was precipitated only in traces by hyperimmune sera (Fig. 5A, lanes 17 and 18 ) as well as by rabbit anti$R I T \cdot D^{\delta}$. Since it was efficiently labeled (lane 2 ) due to its 11 methionines, it was concluded that protein $3 \mathrm{C}$ is a poor antigen.

\section{Discussion}

A procedure is described that produces antisera suitable for the separate indication of FMDV nonstructural proteins 3A, 3C, and 3D, and for the simultaneous indication of proteins $2 \mathrm{C}+2 \mathrm{~B}$, respectively $3 \mathrm{~A}$. The source of the antigens used to raise antisera were bacteria that express defined FMDV-specific polypeptides from recombinant DNA. Such a design of antigens is a safe way to produce antisera directed against specific FMDV polypeptides. We did not try to obtain fusion proteins specific for peptides $2 \mathrm{~A}$ and $3 \mathrm{~B}$, since these are more easily produced by peptide synthesis. All fusion proteins contained only fragments of FMDV proteins (Fig. 2) but nevertheless sufficed, except for one, to elicit antibodies. Exposition of relevant epitopes by protein fragments indicates that the final conformation of respective mature proteins does not result from substantial refolding after completed maturation. In the applied approach we were careful to avoid severe protein denaturation which might have added to the success in epitope conservation within protein fragments being as small as 17 residues. Unsatisfactory results were obtained by the Western blot technique (data not shown), suggesting predominant recognition of conformational epitopes by the antisera.

Specific recognition of nonstructural FMDV proteins was indicated by two serological methods. Indirect immunofluorescence with infected cells was used as a rapid screening test for desired antibodies in sera. Furthermore, this test allows localization of individual FMDV proteins in the cell. All proteins are located exclusively in the cytoplasm, in agreement with the observation that FMDV replication occurs here (1).

While most FMDV proteins, including capsid proteins, are distributed all over the cytoplasm, protein-2C-related antigen preferentially aggregates at the cell periphery. This is observable only transiently about 2 hours post-infection. Similarly located aggregates have been described for cells infected by the Theiler virus in vivo (18), and infection-dependent alteration of the cell surface has been found with Coxsackie B3 virus (19); however, each time it was without specification of the responsible protein. Poliovirus-infected cells, on the other hand, accumulate the $2 \mathrm{C}$ analogue in vesicles built by the endoplasmatic reticulum (20). Different 
intracellular distribution of protein $2 \mathrm{C}$ in FMDV or poliovirus-infected cells makes it difficult at present to attribute a general function to this protein. If there is one, then it is the interaction with cellular membranes.

Indirect immunofluorescence data indicated the absence of $3 \mathrm{C}$ protease from nuclei. Nevertheless, it is not ruled out that minute amounts of enzyme that are not detectable by this method may act efficiently on substrate located there. FMDV-infected cells exhibit a nuclear protein histone $\mathrm{H} 3$ truncated by an unknown proteolytic mechanism (21). 3C protease is bacteriotoxic when expressed from recombinant DNA (22) and accounts for the cleavage of bacterial protein (O.M., manuscript in preparation). The enzyme may likewise account for truncation of histone $\mathrm{H} 3$ in infected cells.

The second method used to analyze the specificity of antisera consisted of precipitation of radiolabeled virus proteins from extracts of infected cells. Agreement with the findings published earlier by others $(2,3,8)$, such as the relationship of precursors to final products and the determination of molecular weights of mature FMDV proteins, was expected and achieved. Minor differences in the molecular weights measured for some proteins are probably due to different experimental setups.

Using this method, FMDV nonstructural proteins $2 \mathrm{~B}, 2 \mathrm{C}, 3 \mathrm{C}$, and 3D, but not $3 \mathrm{~A}$, could be shown to be mature proteins. Maturation of all these proteins requires 3C-mediated proteolysis (5). Evidently, the enzymatic activity is of different efficiency in converting substrates into products: In addition to very rapid proteolysis, which releases precursor $\mathrm{P} 2$ from precursor $\mathrm{P} 3(2,5)$, and other proteolyses of intermediate rapidity, which separate proteins $2 \mathrm{~B}$ and $2 \mathrm{C}, 3 \mathrm{C}$ and $3 \mathrm{D}$, $3 \mathrm{C}$ and $3 \mathrm{~B}_{3}$, there is a proteolysis of low reaction speed observable that separates $3 \mathrm{~A}$ from $3 \mathrm{~B}_{1}$. Different activities of $3 \mathrm{C}$ protease in substrate conversion correlate with the heterogeneity of substrate sites (11). Asynchronous maturation of FMDV proteins may be of biological importance, for example, as a functional regulatory mechanism.

This report indicates different antigenicity of FMDV structural as well as nonstructual proteins in a guinea pig and a cow. The deficiency of antibodies for proteins $2 \mathrm{~B}$ and $2 \mathrm{C}$ in guinea-pig serum observed here confirms earlier observations made by others $(3,6)$. This is not due to low antigenicity of these proteins, since almost all of the 50 investigated bovine postinfectional sera exhibit antibodies for 2C, and most of them also exhibit antibodies for 2B (H.G.B. et al., manuscript in preparation). Nonpermissive mice (BALB/c), which replicate FMDV for a maximum of 60 hours, also develop 2C-specific antibodies, and these are detectable for up to 2 years (data not shown). Underrepresentation of respective antibodies in guinea-pig hyperimmune sera is explained either by immunotolerance or by rapid antigen elimination, as it could be caused by protein degradation.

There are further differences between both types of hyperimmune sera. Only guinea-pig serum efficiently precipitates proteins of about 19,18 , and $15 \mathrm{kD}$ molecular weight. A protein of the latter size is also observed in the extract of infected cells (Fig. 6, lane 1). There is no doubt about the viral origin of these 
proteins, although the two smaller ones differ in size from all of the known mature viral proteins. Since there is no experimental evidence that allows one to assume the production of additional, thus far undetected, virus proteins, it is suggested that these proteins should be considered to be degradation products of already known virus proteins. It remains to identify these proteins.

Other findings concerning titer variances of FMDV-specific antibodies in two animals of different species need confirmation by analyzing a larger number of sera. About 100 bovine sera removed either postvaccination, postinfection, or postchallenge are under current investigation.

\section{Acknowledgments}

This work was partially funded by DFG grant Ma 1009/2-1. We wish to thank our colleagues Drs. R. Ahl, B. Haas, O.C. Straub, and K. Strohmaier for supplying us with FMDV-specific antisera.

\section{References}

1. Rueckert R.R. in Fields BN et al, (eds.) Virology. Raven Press, New York, 1985, pp. 705-738.

2. Doel T.R., Sangar D.V., Rowlands D.J. and Brown F., J Gen Virol 4l, 395-404, 1978.

3. Grubman M.J., Robertson B.H., Morgan D.O., Moore D.M. and Dowbenko D., J Virol 50, 579 $586,1984$.

4. Forss S. and Schaller H., Nucleic Acids Res 10, 6441-6450, 1982.

5. Vakharia V.N., Devaney M.A., Moore D.M., Dunn J.J. and Grubman M.J., J Virol 61, 3199$3207,1987$.

6. Harris T.J.R., Brown F. and Sangar D.V., Virology 112, 91-98, 1981.

7. Grubman M.J., Zeliner M. and Wagner J., Virology 158, 133-140, 1987.

8. Strebel K., Beck E. Strohmaier K. and Schaller H., J Virol 57, 983-991, 1986.

9. Nilsson B., Abrahmsén L. and Uhlén M., EMBO J 4, 1075-1080, 1985.

10. Küpper H., Keller W., Kurz C., Forss S., Schaller H., Franze R., Strohmaier K., Marquardt O., Zaslavsky V.G. and Hofschneider P.H., Nature 289, 555-559, 1981.

11. Forss S., Strebel K., Beck E. and Schaller H., Nucleic Acids Res 12, 6587-6601, 1984.

12. Klump W., Marquardt O. and Hofschneider P.H., Proc Natl Acad Sci USA 81, 3351-3355, 1984.

13. Lieb M., J Mol Biol 16, 149-163, 1966.

14. Towbin H., Staehlin T. and Gordon J., Proc Natl Acad Sci USA 76, 4350-4354, 1979.

15. Williams C.A. and Chase M.W. in Methods in Immunology and Immunochemistry, Vol. 1. Academic Press, London, 1967, pp. 197-307.

16. Marquardt O. and Adam K.-H., Virus Genes 2, 283-291, 1988.

17. Bonner W.M. and Laskey R.A., Eur J Biochem 46, 83-88, 1974.

18. Rodriguez M., Siegel I.M., Hovanec-Burns D., Bologa I. and Graves M.C., Virology 166, 463474, 1988.

19. Lutton C.W. and Gauntt C.J., J Virol 60, 294-296, 1986.

20. Bienz K., Egger D. and Pasamontes L., Virology 160, 220-226, 1987.

21. Grigera P.R. and Tisminetzky S.G., Virology 136, 10-19, 1984.

22. Klump W., Soppa J. Marquardt O. and Hofschneider P.H. in Starlinger P. et al. (eds.) 35 Colloquium-Mosbach 1984. Springer Verlag Berlin, Heidelberg, 1985, pp. 202-209. 